of economic and other specialists, would command high authority. It would express a reasoned opinion for the guidance of Governments as to the wisest and most just plan for the control of world production and the disposal of surpluses, based upon a judicial and expert examination of all the data available. The relatively rich countries could be credited if they so wished, at agreed nominal prices, with any 'gifts' they contributed to the pool, and these credits would be regarded as giving them a call upon the pool at any future time should they themselves be in need.

It is not too soon to consider the setting up of an Advisory Council now. The judges of the Permanent Court of International Justice, seeing that they have established for themselves a reputation for wisdom and impartiality, might be invited to prepare a scheme for the selection of a panel of suitable people to serve upon it. Plans are already under discussion for the feeding and restoration of the famine-stricken inhabitants of European countries. It is too big a task for ourselves and America alone; all countries should take pride in working together for this purpose. It might well be handed over to such a body as the proposed Advisory Council. The disposal of surpluses and the feeding of the hungry are clearly complementary problems : the solution of the first is the key to the solution of the second.

One fundamental difference is to be noted between this approach to post-war problems and the Conference method adopted after the War of 1914-18. We leave the arena of politics, where each nation has its own ends in view, and become intent upon an objective and scientific task: seeking to satisfy, out of our common store, the elemental needs of all peoples. Upon that sound moral and psychological basis it should be possible to go on to build a peaceful World Order.

\section{METEOROLOGICAL RESEARCH IN GREAT BRITAIN}

\section{AIR MINISTRY RESEARCH COMMITTEE}

$\mathrm{T}$ HE importance of meteorology to aviation has necessitated an extension of the State meteorological service far beyond the modest dreams of meteorologists of the last generation. At the present time meteorological forecasting is a vital element in the national war effort, especially in the conduct of the offensive; but the return of peace and the renewed expansion of civil aviation will maintain the need for weather prediction, which also has great importance for agriculture and many other branches of the national economy.

The science and art of weather prediction have made great progress during the present century, but it remains uncertain whether even now all the funda. mental factors that determine the weather changes have been discovered, and also whether the programme of observation yet includes all the elements necessary as a foundation for prediction. The problems both of observation and of theory are extremely complicated. It is therefore desirable that, along with the day-to-day application of the knowledge already available, proportionate efforts should be made to improve our knowledge and our methods.

For this reason the Secretary of State for Air has recently appointed a Meteorological Research Committee to advise and assist in the carrying out of meteorological investigations. The Committee is constituted as follows: Prof. S. Chapman, professor of mathematics at the Imperial College of Science and Technology (chairman); Prof. D. Brunt, professor of meteorology at the Imperial College of Science and Technology; Dr. G. M. B. Dobson, reader in meteorology in the University of Oxford; Prof. G. I. Taylor, Yarrow research professor of the Royal Society; the Director of the Meteorological Office; the Director of Scientific Research of the Ministry of Aircraft Production; the Director of the Naval Meteorological Service; and representatives of the Air Staff and civil aviation.

At present the Committee will naturally be concerned chiefly with problems directly concerned with the war effort, and such work must for the time being remain secret, though any incidental results not likely to be of service to the enemy may be published.

The Committee would welcome contact and cooperation with university departments or other institutions engaged on work that bears on meteorology ; as a result of inquiries in the United Kingdom, information concerning such work, and offers of assistance, have been received from several universities. Correspondence, which should be addressed to the Secretary; Meteorological Research Committee, Meteorological Office, Air Ministry, Kingsway, London, W.C.2, is invited from any other university or research institutions which can assist in this work.

\section{Co-operation of the Royal Society}

The formation of a Meteorological Research Committee by the Air Ministry, announced above, is an important and very welcome advance in the organization of British meteorological research. The Air Ministry Committee will at present confine its work chiefly to those problems which have an immediate practical application and are likely to be solved in a fairly short time. The Royal Society has been invited by the Air Ministry to co-operate with the Meteor. ological Research Committee by undertaking research on certain aspects of meteorology which, though of fundamental importance for the advance of the subject, may not have an immediate practical application.

The Council of the Royal Society has agreed to this request, and has entrusted the immediate responsibility for the work to the Gassiot Committee. This Committee, first constituted in 1871 , was originally appointed to administer the Gassiot and other trust funds applicable to the maintenance of certain British meteorological and magnetic observatories, and to make recommendations as to their work. The terms of reference have now been enlarged to include the supervision of fundamental meteorological research such as has been asked for by the Air Ministry. The personnel of the Committee is appropriate for this purpose; the chairman is Dr. G. M. B. Dobson, and the members are Sir Edward Appleton, Profs. D. Brunt and S. Chapman, Sir Henry Lyons, Sir George Simpson, Prof. G. I. Taylor, Sir Gilbert Walker, the Astronomer Royal, the President of the Royal Astronomical Society, the Director of the Meteorological Office, and ex officio, the Treasurer of the Royal Society (Prof. T. R. Merton) and the Secretary of the Royal Society (Prof. A. C. G. Egerton).

These arrangements seem eminently suitable, because pure fundamental research which may have 
to be continued over a long period, and which requires the co-operation of many independent workers in university departments and laboratories, can probably be organized more easily by the Royal Society than by a Government department, however much the latter may be in sympathy with the object of the researches. The Royal Society has already shown its willingness to further such work by appointing Dr. E. Glückauf to a Mackinnon Studentship, to enable him to carry out meteorological research under the general guidance of the Gassiot Committee.

The general research in which the Air Ministry has sought the co-operation of the Royal Society is that of radiation in the atmosphere, with special reference to radiation equilibrium conditions in the stratosphere. It is fairly generally accepted that the average temperature of the stratosphere-as of the warm region above it-is determined by an equilibrium between the energy absorbed, from both the downward solar radiation and the upward terrestrial radiation, and the energy radiated by the air in the stratosphere. Observations have shown that there are large variations of temperature in the stratosphere both with time and with place, but we know little as to why such variations occur. Few meteorologists, for example, would care to be dogmatic as to why the stratosphere is some $50^{\circ} \mathrm{C}$. colder in equatorial regions than in polar regions.

The principal gases of the atmosphere are mostly very transparent to radiation, and the radiative conditions are largely governed by such minor but polyatomic constituents as water vapour, carbon dioxide, ozone and possibly others. To understand the radiation equilibrium in the atmosphere, it is necessary to know $(a)$ what gases are present which have important absorption bands for radiation; (b) in what proportions they are present at different levels; (c) how gases such as ozone are formed and decomposed ; (d) the absorption coefificients of these gases for different wave-lengths, and whether the absorption and emission spectra have a continuous or fine line structure. Finally, when the above facts are determined, it will be necessary to calculate the radiation equilibrium temperatures at different levels and to determine how rapidly the temperature will change when the conditions alter.

The Gassiot Committee has been fortunate in enlisting expert help in particular branches of the subjects involved, and has formed three sub-committees to deal with different aspects of the above question. It is hoped in this way that the available relevant knowledge will be collected, and that those questions which require more experimental work may be defined, so that arrangements can be made for the work to be done, so far as this should prove possible under present conditions.

Dr. G. M. B. Dobson is the chairman of SubCommittee A, which will deal with the chemical analysis and the observation of the amounts of the polyatomic constituents of the air at different levels ; other members of this sub-committee are Profs. H. Dingle and F. A. Paneth, and Dr. E. Glückauf.

Sub-Committee B will deal with the photophysics and photochemistry of the atmosphere, from the highest levels downwards, and, in particular, with the changing equilibrium of ozone and any other variable polyatomic constituents; the chairman of this sub-committee is Prof. H. W. Massey, and the members are Prof. K. G. Emeléus, Dr. W. C. Price, and Dr. J. Sayers.

Sub-committee $\mathbf{C}$ will consider the radiation balance in the atmosphere ; its chairman is Prof. S. Chapman, and its members are Prof. D. Brunt, Dr. G. S. Callendar, Dr. T. G. Cowling, Dr. A. R. Meetham, Sir George Simpson, and Dr. G. B. B. M. Sutherland.

There will be few who will not agree that the first meteorological problem thus selected for attack is a very important one, and still fewer who will dispute its difficulty. It is hoped that the scientific effort which the Royal Society can bring to bear on this work will lead to substantial progress. The Gassiot Committee is aware that at laboratories and institutions in many parts of the world work has been undertaken that bears on these problems, and the Committee would welcome co-operation in cases where the continuance of such work is possible in present circumstances.

\section{SCIENCE AND TECHNOLOGY IN THE SOVIET UNION}

GCIENCE and technology in the Soviet Union was the subject of the first of the two symposia held over the Easter week-end by the Faculty of Science of Marx House (Marx Memorial Library and Workers' School) at the London School of Hygiene and Tropical Medicine. Prof. J. B. S. Haldane presided and nine speakers took part in the two sessions. The second session, on Race and Fascism, was dealt with in Nature of April 18, p. 426.

Prof. J. D. Bernal spoke on physical science in the U.S.S.R. A great deal of fundamontal work has been done in the Soviet Union and many difficulties have been overcome. In 1920 there wəre only forty trained physicists in the whole country, but by 1934 in the big institutes in Leningrad thero was a six years course which was more rigorous than that in the Cavendish Laboratory. Since then tens of thousands of physicists had boon trained. Physics played a vital part in the general plan of development and in the preparations for the expocted attack on the country.

As an example of the manner in which the funda. mental problems studied arose from the neəds of Soviet economy, Prof. Bernal took the transmission of electric power. Power losses which were trivial in Britain became serious because of the great distances in the Soviet Union. The properties of insulators had to be studied and this required fundamental work on the passage of electricity through crystals and on the quantum theory of the solid state. In the metal industry, also, problems arose which led to a rapid development of crystal physics under Joffe and to the working out of a dynamic theory of plastic deformation. Rehbinder's discovery that the hardness of metals varies according to the surrounding medium is a fundamental one and has already led to changes of technique in dealing with metals.

Science is planned in the U.S.S.R. as a part of economy as a whole on the basis that, statistically, the results will be proportional to the effort applied in any particular field. Only the general requirements are given from outside, and the Academy of Sciences works out in general where the main lines of attack should be made. Each group of workers in each laboratory settles its own problems of how to go about the work. To-day the whole of Soviet science has been turned to the job of winning the War, to the problems of the production and use of 